\title{
LITERATURA EM JOGO: ENSINO DE LEITURA POR MEIO DO RPG
}

\author{
Franciela ZAMARIAM \\ Pós-Graduação em Estudos da Linguagem - Universidade Estadual de Londrina ${ }^{1}$
}

\begin{abstract}
RESUMO: Este trabalho se inscreve na área de ensino da leitura literária e, fundamentado na ideia do "leitor real", de autores como Jouve e Barthes, tem como objetivo discutir uma alternativa metodológica para o tratamento da literatura em sala de aula, uma vez que este tipo de leitura, entre os estudantes, está longe de ser o ideal, em número e em qualidade. $\mathrm{O}$ tema encontra justificativa em uma pesquisa anterior (ZAMARIAM, 2008), realizada com estudantes de escolas públicas estaduais, quando eles confirmaram que as leituras impostas e as provas sobre os livros os faziam rechaçar o texto literário, pois tais atividades os levavam a memorizar informações quanto ao enredo e às personagens, em vez de refletir sobre eles e fruí-los. Como sugestão, os entrevistados afirmaram que as leituras poderiam ser feitas de modo mais dinâmico e envolvente, durante a aula. Dessa forma chegamos à adaptação de obras de literatura para o RPG (jogo de interpretação de papéis), o qual pode proporcionar uma leitura interativa, compartilhada e significativa, sob a orientação do professor, facilitando o acesso a essa linguagem específica, ao mesmo tempo em que reconstrói a afetividade entre leitor e texto. Ademais, verificamos que esse jogo é uma ferramenta transdisciplinar, que leva o aluno a, de fato, vivenciar o enredo da obra. Assim, neste artigo, discutiremos a pesquisa de Mestrado em Estudos da Linguagem (UEL), em andamento, que está sendo realizada com alunos do Ensino Médio da Rede Pública de Educação, sobre o uso do RPG como alternativa metodológica no ensino da leitura literária, cujos resultados se mostraram muito positivos, tanto no quesito motivação, quanto na formação do estudante como leitor maduro. Com isso, pretendemos uma aproximação entre as teorias desenvolvidas na academia e a prática docente na Educação Básica, visando a melhorias no processo de ensino e aprendizagem da leitura nas aulas de Língua Portuguesa.
\end{abstract}

PALAVRAS-CHAVE: Ensino de Leitura, Literatura, RPG.

ABSTRACT: This work is part of the teaching of literary reading and, based on the idea of the "real reader", by authors like Jouve and Barthes, aims to discuss a methodological alternative for the treatment of literature in the classroom, since this Kind of reading, among students, is far from ideal in number and quality. The subject is justified in an earlier research (ZAMARIAM, 2008), carried out with students of state public schools, when they confirmed that the readings imposed and the proofs about the books made them reject the literary text, since such activities led them to memorize information As to the plot and the characters, instead of reflecting on them and enjoying them. As a suggestion, respondents stated that the readings could be done in a more dynamic and engaging way during the lesson. In this way we arrive at the adaptation of works of literature to the RPG (role-playing game), which can provide an interactive, shared and significant reading, under the guidance of the teacher, facilitating the access to that specific language, at the same time in Which reconstructs the affectivity between reader and text. In addition, we verified that this game is a transdisciplinary tool, that leads the student to, in fact, experience the plot of the work. Thus, in this article, we will discuss the ongoing Master's Degree in Language Studies (UEL)

1 Este artigo é parte da pesquisa em andamento para o Mestrado em Estudos da Linguagem: ensino/aprendizagem e formação do professor de língua portuguesa e de outras linguagens. 
research that is being carried out with high school students of the Public Education Network on the use of RPG as a methodological alternative in teaching literary reading, Whose results were very positive, both in motivation and in the student's formation as a mature reader. With this, we intend an approximation between the theories developed in the academy and the teaching practice in Basic Education, aiming at improvements in the teaching and learning process of reading in Portuguese Language classes.

KEYWORDS: Teaching Reading, Literature, $R P G$.

\section{Introdução}

As dificuldades na formação de leitores não são atuais, contudo elas vêm intensificando-se nas últimas décadas, haja vista a revolução tecnológica pela qual passamos desde a década de 1990, unida às transformações conceituais relacionadas ao estudo e ao trabalho da chamada "geração y". Em face dos sedutores aparelhos de alta tecnologia, dos modernos e fascinantes programas computacionais e das redes sociais, as aulas de Língua Portuguesa e a leitura literária parecem, na visão dos adolescentes, atividades obsoletas e com pouca ou nenhuma relação com suas vidas práticas. Por isso, práticas de professores transmissores de conhecimento, alunos receptores e aulas exclusivamente expositivas já não são eficazes.

Por conta da antítese que parece haver entre o ensino de Língua Portuguesa e de leitura e o estilo de vida contemporâneo, o primeiro é visto hoje, pelos estudantes, como necessário apenas para realizar as provas escolares ou passar pelos processos seletivos das universidades, de modo que os alunos, em geral, ao se depararem com um livro clássico ${ }^{2}$, se mostram entediados antes mesmo de abri-lo. De que maneira, então, podemos modificar tal visão, colocar os estudantes em contato com a linguagem literária, bem como com as possibilidades linguísticas trazidas por ela e mostrar-lhes o quanto a leitura pode ser interessante, sem “obrigar-lhes” a ler? Uma possibilidade é através do jogo de RPG.

Como estamos falando de adolescentes, nativos da cultura digital, o RPG, apesar de não ser um jogo tão recente, é uma atividade que traz vários elementos dos recursos digitais, como os já citados anteriormente: a interatividade, liberdade de escolha, o dinamismo, entre outros, além do contato direto com um grupo, outro atrativo para os estudantes.

Dessa forma, neste artigo, iremos discutir a possibilidade de uso do RPG como mediador no ensino de leitura literária, além de utilizá-lo como um meio de "enxergar" as melhorias que podem ser feitas nas aulas de leitura. Ao pensar no jogo como alternativa metodológica para as aulas de literatura, objetiva-se contribuir para a eficácia do ensino de Língua Portuguesa, principalmente no quesito leitura literária, estimulando o envolvimento ativo dos alunos com o mundo dos clássicos, de forma que eles construam um gosto genuíno pela Literatura. Entre outros efeitos, no trabalho que está sendo realizado, espera-se levar os estudantes ao entendimento de que a literatura é arte transdisciplinar, porque abarca conteúdos de diversas áreas de forma não compartimentada, assim como a vida cotidiana, ou seja, é parte importante do universo humano.

\section{Por que buscar uma alternativa e por que o RPG?}

2 Usamos, neste texto, o termo clássico como sinônimo para obra literária canônica, como Dom Casmurro, de Machado de Assim, por exemplo. 
Em uma pesquisa realizada nas escolas públicas de Londrina, em 2008, sobre a relação do adolescente com a leitura literária, para o curso de Especialização em Metodologia da Ação Docente, da UEL (ZAMARIAM, 2008), os depoimentos dos alunos confirmaram que as leituras impostas e as provas sobre os livros só os faziam afastar-se ainda mais da literatura, pois esse tipo de atividade os levava a memorizar informações sobre o enredo e as personagens (muitas vezes, lendo só resumos na Internet), em vez de compreendê-los e fruílos. Como sugestão, a maioria dos alunos entrevistados afirmou que a leitura de obras literárias poderia ser feita de modo mais dinâmico e criativo, na própria sala de aula.

Ora, a adaptação de livros de literatura para "jogos de interpretação de papéis" (RPG, sigla em inglês de role playing games) proporcionou exatamente isto: uma leitura preliminar interativa, divertida e dentro do ambiente escolar, sob a orientação do professor. Contudo, é importante lembrar que o jogo não substitui o livro, mas serve como um motivador para o leitor imaturo à leitura do original, já que o estilo linguístico e a construção estética de cada autor fornecem um aprendizado à parte e indispensável.

Antes de aplica-lo, levantamos várias hipóteses sobre os benefícios do RPG enquanto mediador entre o aluno e a leitura literária. O primeiro deles, como já mencionamos, seria funcionar como um convite à leitura, por meio do conhecimento do enredo, aproximando o estudante do livro, da época e das características de determinada obra, o que talvez nunca ocorresse de outra maneira, a não ser por obrigação. Ao ter esse primeiro contato de forma positiva e divertida, o adolescente poderia constatar que há muito mais em comum entre ele e o livro do que imaginava. Assim, o aluno teria acesso a um universo até então desconhecido, mas significativo, porque o faria descobrir que as obras canônicas o são justamente por sua universalidade, e como tal, possuem características e histórias que podem ter muita relação com sua vida ou com suas aspirações. Além disso, com o RPG, o aluno "viveria" a história e descobriria que literatura é também e, principalmente, afetividade e fruição.

Outra vantagem conjecturada é que esse jogo seria uma ferramenta transdisciplinar, porque ampliaria os conhecimentos de diferentes áreas do conhecimento, como língua portuguesa (linguagem empregada no livro do mestre e nas cartas dos participantes que podem conter traços e fragmentos da obra original); história (dados sobre o contexto sóciohistórico e político em que a obra é ambientada podem ser aproveitados ou acrescentados ao roteiro do jogo); sociologia (costumes da sociedade da época auxiliarão nas interpretações); arte (possíveis referências a artistas, arquitetura, outras obras literárias e artes plásticas contidas na obra e consequentemente no jogo); raciocínio lógico e interpretação textual (tomada de decisões rápidas e resolução de desafios ao longo da campanha); entre outros, tudo isso não compartimentado em disciplinas, mas de uma maneira integrada e mais próxima do aluno.

O RPG estimularia ainda a imaginação ao situar os alunos/jogadores em cidades diferentes das que residem, às vezes, inacessíveis para eles, onde assumem as características das personagens e representam suas ações, "andam" pelas ruas citadas na obra, "vivem" os costumes, "vão" aos lugares mencionados, e "vestem" as roupas da época em que se ambienta a narrativa. Com a representação de personagens clássicas, diferentemente do que acontece na dramatização tradicional (teatro), que limita o agir do ator através de um roteiro fixo, o RPG daria liberdade para a criatividade ao proporcionar espaços para que o jogador tome decisões e preencha lacunas do enredo em sua interpretação de papéis. Mesmo sem modificar os elementos principais da história original, o jogador teria a sensação de que comanda seu destino no jogo, o que é uma característica própria do RPG, como informa em sua dissertação, Farley Pereira (2007): "Por mais livre que seja uma campanha, devemos ter em mente que a 
narrativa "pede" por uma sequência lógica de ações. Assim, um jogador é livre para escolher dentro de uma gama de possibilidades. A total liberdade de escolha é utópica."

Dessa forma, o aluno poderia fazer interpretações do enredo, mas sem fugir da coerência e coesão propostas pelo autor do original. Também desenvolveria sua concentração: qualquer pessoa tem uma retenção muito maior quando há disposição em ouvir, e o RPG faz com que o aluno escute com atenção e tenha interesse em aprender, pois todo detalhe, toda informação é importante para que ele tome suas decisões e viva sua aventura. O jogo ajudaria ainda a melhorar diversos aspectos relacionais, porque exige interação entre os jogadores, uso da entonação adequada da voz e boa expressão facial na interpretação de papéis.

Diante de todos os elementos positivos supracitados, percebemos o RPG como uma ferramenta bastante promissora na motivação da leitura literária, além de auxiliar no desenvolvimento de outras habilidades, como oralidade, interpretação textual e ampliação de vocabulário, já que todo o roteiro do jogo (livro do mestre) pode manter parte do léxico e da literariedade da obra original. Por fim, verificamos também a possibilidade de usar o RPG como "lentes", através das quais seria possível observar elementos do próprio fenômeno da leitura, como o compartilhamento de interpretações, a afetividade em relação a determinadas personagens e ao enredo e a atribuição de sentidos diversos de cada jogador-leitor ao desenvolvimento da narrativa.

\section{O RPG no tempo, na academia e na escola}

Desde que foi lançado, em 1974, nos Estados Unidos, o RPG sempre causou fascínio nas pessoas, sendo o Dungeons \& Dragons, o primeiro RPG com as características que conhecemos, até hoje o mais influente (SCHICK, 1991, apud SCHMIT, 2008, p. 30). No Brasil, essa modalidade de jogo só chegou ao final da década de 1980 (CUPERTINO, 2008), e também aqui tem ganhado um crescente número de adeptos.

Mas afinal, o que é RPG? De acordo com Schmit (2008), em sua dissertação intitulada "RPG e Educação: alguns apontamentos teóricos",

Os jogos de representação (JR), mais conhecidos no Brasil como RPG (Role playing games), são atividades cooperativas nas quais um grupo de jogadores cria uma história de forma oral, escrita ou animada, utilizando-se como plano de jogo a imaginação, esboços, gestos, falas, textos e imagens. Cada um dos jogadores, com exceção de um, representa uma personagem da história, com características próprias pré-definidas. O jogador restante assume o papel de narrador (ou mestre de jogo, entre outros nomes), sendo responsável por descrever o cenário, além de representar todos os coadjuvantes, antagonistas e figurantes, denominados non-player characters ou mais comumente NPC. Não existe competição direta entre os jogadores, sendo, portanto, um jogo de socialização. (SCHMIT, 2008, p. 23)

A definição de Schmit deixa claro que as características do jogo de representação de papéis são, por si só, propícias à aprendizagem, não havendo necessidade de didatizá-lo. Adaptar uma obra literária clássica a esse tipo de jogo o mantém em seu campo de domínio: as narrativas de aventuras.

Por sua relação com a área das letras, outras pesquisas acadêmicas se voltaram para o RPG, porém com objetivos distintos do proposto aqui, sendo os temas mais recorrentes: a comparação desse jogo com a literatura (PRIETTO, 2013; PEREIRA, 2007; MOTA, 2004) ou 
ainda o RPG como suporte de leitura (PAVÃO, 1999). Entretanto, o trabalho que mais nos chamou a atenção sobre o assunto é a dissertação de Mestrado (USP), de Thomas Massao Fairchild, defendida em 2004, intitulada "O discurso de escolarização do RPG". Nela, o autor se propôs a estudar entrevistas com jogadores e debates realizados na Internet, sobre os quais critica as chamadas "frases feitas". Nessas críticas, Fairchild (2004) contradiz alguns resultados esperados do RPG, como o de que RPGistas são bons leitores porque precisam pesquisar para jogar ou porque leem de tudo indistintamente para realizar suas práticas:

\begin{abstract}
Ao se exaltar o hábito de ler dos RPGistas, chega-se facilmente à ideia de que toda leitura é boa e silencia-se o fato de que há também leituras obedientes, leituras ingênuas, leituras não-significativas. [...] Essa ideia talvez decorra de uma interpretação equivocada do que as teorias cognitivistas da leitura propuseram para o ensino de língua, relativizando a importância do estudo dos textos canônicos. $\mathrm{O}$ equívoco está justamente em supor que, se tais textos [bulas, notícias etc.] têm a atenção da escola, sua leitura extensiva baste para a formação de um bom leitor. Parece-nos que o ensino de leitura deve passar por uma diversidade de textos e gêneros, da qual não se quer excluir leituras como a do RPG, mas que não deve se totalizar nelas. (FAIRCHILD, 2004)
\end{abstract}

Justamente pensando em não restringir o universo de leituras do aluno é que propomos aqui um trabalho sobre o resgate da literatura canônica, através, inicialmente, de sua adaptação para um roteiro de RPG, haja vista que não se deve começar uma formação por clássicos, mas também não podemos simplesmente deixá-los de lado, diante de todos os benefícios que propiciam, conforme explana Ítalo Calvino (1993):

\begin{abstract}
Um clássico é um livro que nunca terminou de dizer aquilo que tinha para dizer. [...] Os clássicos são aqueles livros que chegam até nós trazendo consigo as marcas das leituras que precederam a nossa e atrás de si os traços que deixaram na cultura ou nas culturas que atravessaram (ou mais simplesmente na linguagem ou nos costumes). [...] Um clássico é uma obra que provoca incessantemente uma nuvem de discursos críticos sobre si, mas continuamente as repele para longe. [...] O "seu" clássico é aquele que não pode ser-lhe indiferente e que serve para definir a você próprio em relação e talvez em contraste com ele. (CALVINO, 1993, p. 9 - 13; 16)
\end{abstract}

Como assegura Antonio Cândido (1999), em seu célebre texto "A literatura e a formação do homem", a arte literária possui função humanizadora, e a catarse propiciada pela vivência das narrativas clássicas através do RPG auxilia no cumprimento dessa função.

Assim, com essa ferramenta, pretendemos oportunizar um contato significativo do estudante/jogador com as obras canônicas, não apenas conhecendo-a, mas vivenciando-a, interpretando-a, preenchendo suas lacunas, "brincando" com os enredos e fazendo outras tantas leituras possíveis. Além disso, com o RPG, professor e aluno não mais desempenharão os costumeiros papéis de "detentor do conhecimento e ouvinte", mas serão organizador e participante, respectivamente, podendo mudar de papéis segundo lhes convier (desde que o professor se mantenha como norteador e mediador da aprendizagem). Ademais, esse jogo possibilita o real emprego do sociointeracionismo de Vygotsky dentro da sala de aula, pois o RPG é necessariamente social, induz à cooperação entre os participantes e incentiva naturalmente $\mathrm{o}$ ato de ler e de aprender.

\title{
3 Literatura em jogo
}


Ainda que o conceito de cânone literário já não encontre na própria crítica total firmeza para sustentar-se (SAID, 1995, apud MAFRA, 2003, p. 3) é fato que as obras clássicas continuam sendo cobradas nos programas de ensino governamentais, em exames de ingresso a universidades e em concursos para o funcionalismo público. Ademais, nunca se pode esquecer a fruição, a criticidade e a humanização que podem ser alcançadas por meio do texto literário.

Por outro lado, em pesquisa anterior com alunos do último ano do Ensino Fundamental (ZAMARIAM, 2008), constatamos que não é possível formar um leitor "empurrando-lhe" um clássico da literatura, uma vez que o adolescente que nunca teve contato com esse tipo de texto não tem subsídios lexical, sintático e estilístico para compreendê-lo e, por conseguinte, para aprender e fruir com sua leitura. Ao contrário, a obrigação de realizar uma atividade que não lhe parece interessante tampouco significativa, só o fará rechaçar cada vez mais a leitura dos clássicos.

E é exatamente isso que vemos atualmente, inclusive com alunos do Ensino Médio, que ali chegam, em sua maioria, sem o hábito de ler nem o gosto pela prática ou se mantém presos unicamente a best sellers, cujos leitores, devido à precária formação, ainda não atingiram a maturidade linguístico-literária suficiente para consumirem também os clássicos. Tais problemas derivam de que "o ensino de literatura nas escolas de ensino médio vive hoje um grande impasse. Herdeiro de uma visão clássica de literatura, é prisioneiro de um anacronismo que o distancia do aluno." (MAFRA, 2003, p. 4).

A afirmação de Mafra demonstra como o ensino nessa área tem sido conduzido de maneira inadequada, à medida que rejeitamos leituras consideradas "de massa", por considerá-las pouco proveitosas, e já no início da formação do leitor exigimos que ele leia uma obra canônica, sem uma metodologia apurada.

Apoiando-nos nessa ideia, chegamos ao RPG como alternativa metodológica para o ensino de leitura literária. Uma vez que essa atividade não deve ser imposta, o jogo de papéis pode funcionar como uma introdução ao texto clássico, dando ao adolescente uma prévia do enredo (o que facilitará a compreensão da obra original), aguçando-lhe a curiosidade e despertando-lhe o desejo de ler.

Diversas tentativas com outros formatos e o mesmo objetivo já foram realizadas, mas sem o sucesso desejado, porque focavam no leitor imaturo sem desprender-se das formas tradicionais de leitura. Ainda assim, tais adaptações funcionam como ponto de partida, para que possamos refletir sobre a eficácia da parceria "jogo e literatura", desde que esteja alinhada aos conceitos da cultura vigente, ou seja, a cibercultura ${ }^{3}$.

Algumas obras foram transpostas para diferentes gêneros, escritos ou mesmo jogos. Disponíveis em quadrinhos, por exemplo, estão livros como "O Cortiço", de Aluísio Azevedo e o conto "A Causa Secreta", de Machado de Assis; e em jogos virtuais, podemos encontrar também "O Cortiço", "Dom Casmurro", de Machado de Assis, e "Memórias de um Sargento de Milícias”, de Manuel Antônio de Almeida (CRUZ, 2013), cuja principal ação proposta ao jogador é clicar em objetos da cena para ler fragmentos do livro.

Em consonância com Celso Santiago, gestor cultural e organizador das adaptações para jogos virtuais:

\footnotetext{
${ }^{3}$ A cibercultura ou cultura digital pode ser compreendida como "a forma sociocultural que emerge da relação simbiótica entre a sociedade, a cultura e as novas tecnologias de base micro-eletrônica", ou seja, é "a cultura contemporânea marcada pelas tecnologias digitais" (LEMOS, 2003, p. 11).
} 
Depois da experiência de utilizar um material multimídia em um curso para educadores sobre o livro Macunaíma, vi que a possibilidade de unir esses universos poderia ser bem interessante. E comecei aí a pensar em trabalhar com games. Além disso, muitos jovens veem a literatura como obrigação. Pelo contrário, a literatura é prazer, é se envolver, é descobrir. (apud CRUZ, 2013)

Completando o pensamento de Santiago, Gilson Schwartz, professor da USP e diretor da Games for Change na América Latina, garante que os jogos, de modo geral, "ajudam a desenvolver o cérebro como se estivéssemos numa academia, auxiliando nos processos de ensino e aprendizagem" (apud CRUZ, 2013).

Nessa mesma linha de raciocínio, uma pesquisa realizada na Escola de Comunicações e Artes (ECA) da USP investigou os jogos como formas de linguagem audiovisuais. Uma das constatações é a de que eles extrapolam os limites do entretenimento, mudando a maneira como as pessoas se relacionam com o conhecimento:

\begin{abstract}
Os jogos, sejam digitais ou analógicos, são endêmicos e associados diretamente ao ser humano. As pessoas sempre vão jogar, seja com um osso, como na Antiguidade, seja com um holograma e raio laser, no futuro. [...] Os jogos, cada vez mais, mudam a forma de nos relacionarmos com o conhecimento, com a comunicação, pois inspiram e fomentam bases de interface associadas a novas práticas comunicacionais, o que não pode ser ignorado. (CORRÊA, 2013)
\end{abstract}

Durante o estudo, o pesquisador descobriu que um jogo não é somente um jogo. Segundo Corrêa (2013), os "games" modificam a compreensão de mundo dos jogadores, e se forem vistos como uma ferramenta de formação, podem ampliar as relações das pessoas com o conhecimento, permitindo uma nova maneira de aprendizagem, melhorando significativamente a qualidade do ensino em nosso país. Isso já é uma realidade em outras partes do mundo, segundo a publicação realizada em 28 de fevereiro de 2014, de Ana Paula Souza, da Agência de Notícias USP, que noticiou o trabalho de Gomes (2013):

[...] em viagens à Ásia e aos Estados Unidos para participar de eventos sobre artes marciais, o pesquisador conheceu uma série de tendências relacionadas ao universo gamer, entre elas os serious games, que são jogos voltados à educação e aplicados em diversas instituições de ensino. (SOUZA, 2014)

Não é por acaso que Wittgenstein escolhe o conceito de jogo para analisar a linguagem, concluindo que um significado só é definido quando posto em uso, ou melhor, em "jogo" (WITTGENSTEIN, 2000). Também a literatura, um tipo específico de linguagem, só terá significado se for "jogada", no sentido de que no jogo não nos obrigamos, mas nos propomos a jogar, porque o desejo precisa ser voluntário. Não é forçando-nos a aprender que nos fazem desejar aprender. Ao leitor maduro, o livro em si já proporciona esse "jogo", mas para o leitor em formação, algumas adaptações são necessárias, como a que propomos aqui, através de um jogo mais específico e claro na visão do adolescente.

Em 1938, o filósofo Huizinga (1999) já argumentava, em seu livro Homo Ludens, que o jogo é uma categoria absolutamente primária da existência, tão essencial à vida quanto o é o raciocínio e a fabricação de objetos, portanto o elemento lúdico estaria na base das origens e do desenvolvimento da civilização. 
Desde a infância, o jogo é parte de nosso processo de desenvolvimento cognitivo e motor, e mesmo na vida adulta, diferentes tipos de jogos são realizados com objetivos diversos: nos relacionamentos (jogos de sedução, jogos de convencimento), no trabalho (competições por um cargo ou por uma premiação de melhor funcionário), entre outros.

Para Vygotsky (1991), o jogo tem papel fundamental no desenvolvimento do ser humano. Assumindo que o aprendizado se dá por interações, o jogo de papéis atua na zona de desenvolvimento proximal do indivíduo, criando condições para que conhecimentos e valores sejam consolidados durante o exercício das capacidades de imaginar situações, representar papéis e seguir regras de conduta de sua cultura (na brincadeira de "mamãe e filhinha", por exemplo, só a mamãe que pode colocar a filhinha de castigo). Assim, no espaço escolar, o jogo pode ser um catalisador do desenvolvimento integral dos alunos,

Seguindo o raciocínio de Vygotsky, Prado (1991, p. 78), elenca alguns elementos próprios do lúdico presente nos jogos: o desejo (enquanto motivação intrínseca do sujeito); a afetividade; a situação imaginária e a interação criativa (reciprocidade não passiva e criadora). De opinião semelhante, Almeida (1998, p. 31-32), entende as atividades lúdicas como integradoras de "uma teoria profunda e uma prática atuante", cujos objetivos

[...] além de explicar as relações múltiplas do ser humano em seu contexto histórico, social, cultural, psicológico, enfatizam a libertação das relações pessoais passivas, técnicas para as relações reflexivas, criadoras, inteligentes, socializadoras. (ALMEIDA, 1998, p.31-32)

Corroborando com a ideia de Almeida, a pesquisa de Santos (1997, p.12) explicita o caráter potencializador dos jogos para o desenvolvimento pessoal, cognitivo, lingüístico, emocional e cultural das pessoas, melhorando sua socialização, comunicação e autonomia na construção da aprendizagem. Tais efeitos tiveram confirmação na publicação de 09 de junho de 2014, do site Desafios da Educação, mantido, no Brasil, pelo Grupo A, e consultor de importantes Instituições de Ensino, como a FGV: "o jogador costuma ter um nível de atenção muito elevado durante uma partida, e é muito interessante para o professor saber utilizar isso em prol de aprendizado estudantil". Além disso "[...] o uso de jogos na sala de aula pode incrementar o aprendizado em 20\%" (DESAFIOS DA EDUCAÇÃ̃O, 2014).

O RPG se encaixa perfeitamente em todos esses benefícios e vai além, porque torna a aprendizagem deveras significativa, uma vez que não tem um cunho estritamente didático, possuindo verossimilhança. Cremos que, nessa característica, encontra-se uma grande vantagem do RPG, pois jogos exclusivamente produzidos para ensinar determinado conteúdo correm o risco de se tornarem desinteressantes. Ao passo que uma adaptação de um livro para um jogo de papéis pode ser apreciada dentro e fora da escola, por estudantes ou adolescentes em um encontro social, dada a manutenção de sua característica essencial: uma aventura ambientada em uma época e em um espaço diferentes dos vividos pelos participantes.

\section{Produção e aplicação do jogo}

Durante a preparação para o Eureka 2014, evento do colégio Sesi de BandeirantesPR (Ensino Médio), que se propõe a divulgar inovações de diferentes tipos, embasadas em projetos científicos realizados por professores e alunos, surgiu a ideia de adaptar o conto "A Cartomante", de Machado de Assis, a um jogo de representação de papéis (RPG), para estimular o gosto pela leitura de uma maneira divertida e inovadora. Feita a pesquisa de 
anterioridade, conforme exige o evento, constatamos que nada do tipo havia sido criado antes, existindo apenas pesquisas teóricas a respeito ou aplicações com outros temas e/ou objetivos.

A partir de pesquisas sobre o contexto em que obra "A Cartomante" é ambientada e o funcionamento do jogo em questão, produzimos, em conjunto com a professora Edilaine Delgado, também de Língua Portuguesa, e em parceria com o professor e jogador de RPG, Márcio Massashiko Hasegawa (UENP), um "Livro do Mestre" e as cartas dos jogadores, mantendo parte do estilo e fragmentos da obra original.

Após o término dessa etapa, buscamos um jogador "profissional" de RPG a fim de assistir-lhe em ação. Denominamos esse momento de "aperfeiçoamento do material", uma vez que, depois de ver o RPG sendo jogado por um especialista, verificamos que ainda eram necessárias algumas modificações em nosso trabalho. Feito isso, o jogo estava pronto para ser aplicado, para o que marcamos a campanha com os estudantes.

Para a etapa da aplicação do RPG, convidamos três grupos de quatro alunos cada para comporem as sessões de jogo. Tal seleção foi realizada com base em questionários, aplicados a 77 estudantes do primeiro ano do Ensino Médio de uma escola pública. A pergunta norteadora de nossa escolha foi uma das primeiras ${ }^{4}$ : "você gosta de ler?". Buscamos focar nos alunos que responderam "não", mesclando-os a pelo menos um em cada grupo que se mostrou leitor assíduo. Tal critério foi pensado a fim de que o jogo não ficasse estagnado em certos momentos, imaginando que os leitores teriam mais capacidade de tomar decisões.

Escolhemos uma sala de aula vazia para a aplicação, em cujas paredes foram coladas diversas imagens relacionadas à época do conto "A Cartomante", base de nosso enredo, para criar a ambientação necessária à ativação dos conhecimentos prévios e da memória dos participantes. Em cada campanha, nos colocamos como "o mestre", personagem responsável pela leitura do enredo, que não interfere diretamente na narrativa senão para atribuir pontuações e oferecer opções aos jogadores.

O trabalho foi muito produtivo, pois pudemos verificar a comprovação da maioria das hipóteses levantadas. O jogo proporcionou aos leitores as antecipações que fazemos na leitura literária, além de despertar concordâncias ou discordâncias explícitas com as atitudes das personagens, ou seja, despertou a afetividade. Estimulou ainda a criticidade dos alunos, ao julgarem seus próprios valores morais em contraposição aos das personagens e às decisões dos colegas. Surgiram comentários e questionamentos bastante relevantes como: "eu serei a mulher, eu sou transexual?" (garoto falando); "nossa, com essas características eu sou a pior pessoa do mundo!"; "eu sou perfeita para esse personagem."; e "eu vou agir assim, porque sou um homem de palavra, leal! [característica dele no jogo]".

Outra observação interessante é que uma vez criada a ficha de personagem sob as bases das características das personagens originais, as ações variaram, mas todas ficaram em torno do caráter de cada figura. Às vezes, os alunos perceberam que certas ações são mais condizentes com a personalidade da personagem do que o que está descrito no conto. Nesse quesito, um comentário interessante foi: “professora, na época eles não eram muito católicos no Brasil? Então, como eu sou muito correto e nos 10 mandamentos fala que não pode matar, não vou matar ninguém...”

Nas falas dos alunos percebemos como eles se envolveram nessa "leitura" preliminar e como compreenderam a dinâmica do enredo, da época e do texto literário em questão durante a campanha de RPG, independentemente de serem leitores ou não. Em primeira

\footnotetext{
${ }^{4}$ Ver questionário anexo.
} 
análise, ainda superficial, não percebemos diferença significativa de desempenho no jogo entre o aluno que lê muito, o que lê pouco ou o que não gosta de ler, refutando uma das ideias iniciais. O resultado esteve mais ligado à personalidade (timidez, extroversão, "esperteza", "pouca criatividade" etc.) de cada aluno, contudo os "leitores maduros" eram mais refinados em suas decisões.

\section{Considerações Finais}

Depois de jogadas as três campanhas, com os três grupos distintos, constatamos que não é possível falar em "o leitor", no singular, já que os leitores diferem muito entre si, em sua complexidade, em suas interpretações e vivências, haja vista os diversos e criativos finais que cada campanha obteve. Tal afirmação já havia sido feita por Barthes (2002), quando trata da complexidade do fenômeno da leitura por conta da multiplicidade de elementos que compõem os leitores. Também é o que Jouve (2002) propõe em sua obra, quando aprofunda seu entendimento de leitor, fugindo da concepção dos teóricos da Estética da Recepção como Jauss, que pensavam o leitor como alguém genérico, não real.

Ainda que a pesquisa esteja em andamento, já é possível afirmar, a priori, que o RPG não é um motivador qualquer para a leitura, como brincadeiras e cenografias sobre um livro. É um momento muito importante de aproximação entre leitor e texto literário, para contato com o enredo e com pequenos trechos do original, a fim de mostrar que a literatura em si é um jogo e que é, sim, fruição. É ainda uma lente através do qual o professor pode enxergar o que seus alunos precisam para se tornarem leitores literários. O jogo não é substituto do livro, mas é uma forma de recuperar a afetividade do estudante com a literatura e de realizar uma leitura preliminar coletiva. A expectativa é de que, mais do que um motivador espontâneo, o RPG funcione como uma base para leituras consideradas difíceis pelos adolescentes, como se fosse um degrau, um passo a mais até a fruição madura do texto literário na trilha para a maturidade leitora. Espera-se, assim, que com esta metodologia, haja uma contribuição significativa para a formação literária tardia do leitor.

\section{Referências}

ALMEIDA, P. N. Educação lúdica: técnicas e jogos pedagógicos. São Paulo: Loyola, 1998.

ANDRÉ, Marli Elisa; LUDKE, Menga. Pesquisa em educação: Abordagens Qualitativas. São Paulo: EPU, 1986.

BARTHES, R. O prazer do texto. 3. ed. São Paulo: Perspectiva, 2002.

CALVINO, Ítalo. Por que ler os clássicos. São Paulo: Companhia das Letras, 1993.

CÂNDIDO, Antônio. A literatura e a formação do homem. In: Remate de males. Número Especial Antonio Candido. Campinas: Departamento de Teoria Literária IEL Unicamp, 1999.

CORRÊA, Francisco Tupy Gomes. Videogame como linguagem audiovisual: compreensão e aplicação em um estudo de caso - super street fighter. 2013. 121 fls. Dissertação (Mestrado em Meios e Processos Audiovisuais) - Universidade de São Paulo, São Paulo, 2014. 
CRUZ, Bruna Souza. Clássicos da literatura brasileira viram jogos virtuais. UOL: São Paulo. 17 maio 2013. Disponível em: 〈http://educacao.uol.com.br/noticias/2013/05/ 17/tresclassicos-da-literatura-brasileira-viram-jogos-virtuais.htm>. Acesso em: 01 out. 2014.

CUPERTINO. Edson Ribeiro. Vamos jogar RPG? Diálogos com a literatura, o leitor e a autoria. 2008. Dissertação (Mestrado em Literatura) - Universidade de São Paulo, São Paulo. Disponível em: <http://www.teses.usp.br/teses/disponiveis/8/8156/tde-13022009-122722/ptbr.php>. Acesso em: 28 set. 2014.

DESAFIOS DA EDUCAÇÃO. Jogos são tendência inovadora na educação. 09 jun. 2014. Disponível em: <http://www.desafiosdaeducacao.com.br/jogos-sao-tendencia-inovadora-naeducacao/> Acesso em: 28 set. 2014.

FAIRCHILD, Thomas Massao. $O$ discurso de escolarização do RPG. 2004. Dissertação (Mestrado) - Universidade de São Paulo, São Paulo. Disponível em: <http://www.pesquisarpg.ufpa.br/material/rpg-mestrado-FAIRCHILD- Thomas.pdf>. Acesso em: 28 set. 2014.

HUIZINGA, J. Homo ludens: o jogo como elemento da cultura. Perspectiva: São Paulo, 1999.

JOUVE, Vincent. A leitura. São Paulo: Editora da UNESP, 2002.

LEMOS, André. CIBERCULTURA: Alguns pontos para compreender a nossa época. In:

LEMOS, André; CUNHA, Paulo (orgs). Olhares sobre a Cibercultura. Porto Alegre: Sulina, 2003. p. 11-23.

MAFRA, Núbio Delanne F. Leituras à revelia da escola. Londrina: Eduel, 2003.

MOTA, Sônia Rodrigues. Role Playing Game e a Pedagogia da Imaginação o Brasil. Rio de Janeiro: Bertrand Brasil, 2004.

PAVÃO, Andréa. A Aventura da Leitura e da Escrita entre Mestres de Role Playing Games (RPG). UFPA, 1999. Disponível em: <http://pesquisarpg.ufpa.br/material/rpg-artigoPAVAO-Andrea.pdf>. Acesso em: 25 set. 2014.

PRADO, Marysia M. Rodrigues do. Des-cobrindo o Lúdico. Dissertação (Mestrado em Educação), $\quad$ FE/UNICAMP, $1991 . \quad$ Disponível em: <http://www.bibliotecadigital.unicamp.br/document/?code=vtls000030390 >. Acesso em: 17 set. 2014.

PEREIRA, Farley Eduardo Lamines. No limite da ficção: comparações entre literatura e RPG - Role Playing Games. 2007. Dissertação (Mestrado em Estudos Literários) - Universidade Federal de Minas Gerais, São Paulo. Disponível em: <http://www.bibliotecadigital.ufmg.br/dspace/bitstream/handle/1843/ECAP72BKDN/dissertacaofinalb.pdf;jsessionid=D4F7EA9D3BA416B819064A1A1CC254D9?seq uence $=1>$. Acesso em: 17 set. 2014 .

PRIETTO, Thiago Goulart. Literatura e os jogos de RPG: Trajetória de apropriações e intertextos. Revista Translatio, Porto Alegre, n. 6. 2013. Disponível em: 
〈http://www.seer.ufrgs.br/index.php/translatio/article/view/44670/28368 $>$. Acesso em: 01 out. 2014.

SANTOS, Santa Marli Pires dos. Brinquedoteca: o lúdico em diferentes contextos. Petrópolis: Vozes, 1997.

SOUZA, Ana Paula. Videogames já não servem apenas para diversão. Agência USP de Notícias, 28 fev. 2014. Disponível em: 〈http://www.usp.br/agen/?p=169453〉. Acesso em: 19 set. 2014.

SCHMIT, Wagner Luiz. RPG e Educação: Alguns apontamentos teóricos. 2008. Dissertação (Mestrado em Educação). Universidade Estadual de Londrina, Londrina. Disponível em: <http://www.uel.br/pos/mestredu/images/stories/downloads/ dissertacoes/2008/2008\%20\%20SCHMIT,\%20Wagner\%20Luiz.pdf>. Acesso em: 13 set. 2014.

VYGOTSKY, L. S. A formação social da mente. São Paulo: Martins Fontes, 1991.

WITTGENSTEIN, Ludwig. Investigações filosóficas. Tradução de José Carlos Bruni. São Paulo: Nova Cultural (Col. Os Pensadores), 2000.

ZAMARIAM, Franciela S. A Relação do Adolescente com a Literatura na Era da Cultura Digital: Um Estudo sobre a Leitura em Escolas Estaduais de Londrina. 2008. Monografia (Especialização em Metodologia da Ação Docente) - Universidade Estadual de Londrina, Londrina, 2008. 


\section{Universidade \\ Estadual de Londrina \\ MESTRADO EM ESTUDOS DA LINGUAGEM \\ FRANCIELA SILVA ZAMARIAM}

\section{QUESTIONÁRIO}

1 - Qual sua atividade de lazer favorita?

2 - Você gosta de ler?
( ) Sim
( ) Não

3 - Se você respondeu SIM para a pergunta anterior, o que você gosta de ler?

4 - Até o $9^{\circ}$ ano, os professores exigiam que você lesse livros de literatura?

( ) Sim ( ) Não

5 - Se SIM, o que você acha dessa exigência?

( ) concordo totalmente

( ) concordo parcialmente

( ) indiferente

( ) discordo parcialmente

( ) discordo totalmente

Por quê?

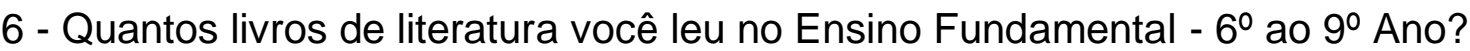

$\begin{array}{llllll}\text { ( ) Nenhum ( ) De } 1 \text { a } 3 & \text { ( ) De } 4 \text { a } 6 & \text { ( ) De } 7 \text { a } 10 & \text { ( ) Mais de } 10\end{array}$

7 - Cite os livros de que você mais gostou.

8 - Houve algum livro que leu, mas não entendeu? Se sim, quais?

9 - A seleção dos livros trabalhados no Ensino Fundamental - 6ำ ao 9ำ Ano era feita por quem?

( ) Pelo professor

( ) Por você

10 - Quando é solicitada, na escola, a leitura de um livro, você busca resumos do mesmo livro na Internet?

( ) $\operatorname{Sim}$

( ) Não 
11 - Se você respondeu SIM na questão anterior, o resumo da Internet serve para:

( ) Facilitar o entendimento do livro, após sua leitura

( ) Substituir a leitura do livro em alguma avaliação

12 - Fora as exigências da escola, você costuma ler?

( ) Sim

13 - Cite os livros de literatura que você já leu:

14 - Em uma escala de 1 a 5, sendo 5 o mais frequente e 1 nunca, diga os motivos para suas leituras de livros literários:
( ) Prazer / decisão própria
( ) Avaliação escolar
( ) Exigência familiar

15 - Em uma escala de 1 a 5 , sendo 5 o mais frequente e 1 nunca, informe como era feita, pelo professor, a cobrança sobre o livro que você leu, durante o Ensino Fundamental?

( ) Prova escrita apenas sobre o enredo do livro

( ) Prova escrita contemplando suas impressões pessoais

( ) Prova oral apenas sobre o enredo do livro

( ) Prova oral tratando de suas impressões sobre o livro

( ) Roda de leitura (momento mais "descontraído" para tratar dos livros lidos)

( ) Discussão em sala sobre os assuntos contidos na obra lida

( ) Redação

( ) Outros. Especifique:

16 - Quais benefícios você percebe na leitura de literatura?

17 - Que outras atividades escolares você preferiria fazer ao invés de ler? Por quê?

18 - O que você acha que poderia melhorar nas aulas de leitura para despertar o interesse da turma pela literatura?

( ) Mais provas de leitura

( ) Mais debates relacionando o livro a sua vida

( ) Jogos e outras atividades lúdicas contemplando a leitura literária

( ) Outros. Especifique:

19 - Como você acha que deveria ser cobrada a leitura de vocês?

( ) Com provas

( ) Com debates orais

( ) A leitura não deveria ser cobrada

( ) Outros. Especifique:

20 - Justifique sua resposta à questão anterior. 
VI CLAFPL

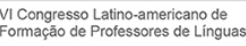

